\title{
Production of Dye from Green and Brown Walnut Shells for Leather Coloration
}

\author{
Neslihan Doğan-Sağlamtimur ${ }^{1}$, Ersen Turaç ${ }^{2}$, Ruhsar Arabacioğlu ${ }^{1}$, Tuğba Çivioğlu ${ }^{1}$ \\ ${ }^{1}$ Department of Environmental Engineering, Omer Halisdemir University, Nigde, 51240, Turkey \\ ${ }^{2}$ Department of Chemistry, Omer Halisdemir University, Nigde, 51240, Turkey
}

\begin{tabular}{l} 
Article Info \\
\hline Article history: \\
Received June $13^{\text {rd }}, 2017$ \\
Revised June $15^{\text {th }}, 2017$ \\
Accepted June $17^{\text {th }}, 2017$ \\
\hline
\end{tabular}

Keyword:

Dye

Environment

Leather

Reuse

Walnut

Waste

\begin{abstract}
Nowadays, it is observed that there is an increasing approach to the use of natural substances instead of synthetic ones. As the synthetic materials and products are more complex in comparison to natural substances, it will take a long time to complete their natural cycles and return to nature, thus, causing a lot of environmental pollution.Green and brown shells of walnuts that are not only valuable crops but also important components of the Mediterranean dietare by-products of the walnut production, having scarce use (especially green shell). Thus, using shells as a source of dye will increase the value of the walnut production, as well as offering utilization for a by-product, which is produced in large quantities. The purpose of this study is to produce dye from wastegreen and brown walnut shells, compare quality of these dyesand apply themseparately in untreated leather. Before chemical processes, the walnut shells were chopped in a grinding mill. They were dried in an oven toeliminate the humidity and extracted inSoxhlet apparatus by using ethanol solution. Then,the ethanol solution was evaporated in controlled way and the produced dyes weremordanted by using potassium aluminium sulphate (PAS). The dyes were analysed by TLC and UV-Vis, whereas dyed leathers were analysed by colorfastness test. The present study showed that brown walnut shell dye having higher color values was better for yield, dye penetration and fastness properties compared to green walnut shell dye.Luminous effect was observed when these dyes were applied in leather. It is interesting, uncommon and economically valuable for leather industry.This study would be a positive step to meet the need of leather industry in Turkey and a good example for cleaner production.
\end{abstract}

\section{Corresponding Author:}

Neslihan Doğan-Sağlamtimur,

Department of Environmental Engineering,

Omer Halisdemir University,

Nigde, 51240, Turkey.

Email: neslihandogansaglamtimur@gmail.com

\section{Introduction}

Nuts are important components of the Mediterranean diet. Juglans regia Linn (Juglandaceae), which is known as the walnut, is a tall deciduous tree of about 20 meters-in-length [1]. Walnuts are widely distributed all over the world, and in Turkey, these species are common along the country. The Juglans genus (family Juglandaceae) comprises several species and spreadsall over the world. The walnut tree (Juglans regia L.) is its well-known member, constituting an important species of deciduous trees found primarily in temperate areas. It is cultivated commercially throughout southern Europe, northern Africa, eastern Asia, United States and western South America. In Turkey, walnut trees can be found all over the country, being the nuts very popular and largely consumed as part of the Mediterranean diet. Walnut green shell is a by-product of the 
walnut production, being formed in large amounts. Probably due to its scarce utilization, this matrix is very little studied [2].

Our world is reaching to new high horizons with the growth of mankind, society, science and technology but the cost which we are paying or will pay in near future is surely going to be too high. Among the consequences of this rapid growth is environmental disorder with a big pollution problem [3]. The pollution control is one of the prime concerns of society today. Untreated or partially-treated wastewaters including dyes from various industrial effluents into natural ecosystems pose a serious problem to the environment. One of the important class of the pollutants is dyes, and once they enter the water it is no longer good and sometimes difficult to treat as the dyes have a synthetic origin and a complex molecular structure which makes them more stable and difficult to be bio-degraded $[4,5]$. Synthetic dyes have complex aromatic structures which are widely used in the industries such as textiles, rubber, paper, plastics, food, and cosmetics to color their products [6]. These dyes are harmful to fauna, flora, and some of dyes and their products have a mutagenic or carcinogenic influence on human beings [7]. Even at low concentrations, dyes could be highly noticeable, and can cause an aesthetic pollution and disturbance to the ecosystem and water sources [8]. Hence, removal of these compounds from the effluents is necessary.

The worldwide use of walnut green leaves and shells for natural dyeing of textiles has ancient roots. During the last years, an increased interest was noted for the use of natural dyes in textile dyeing process. Recent studies drew the specialists' attention since natural dyes were found to have, besides coloring properties, good insecticidal effects-thus helping to the fiber protection [9]. The walnut shell that is used as a coloring agent belongs to the group of nutshells, a class of highly insoluble species. It has antibacterial properties.

Natural dyes are mostly eco-friendly, renewable, biodegradable, less toxic and less allergenic as compared to synthetic dyes [10]. Still the use of natural dyes involves some disadvantages such as requirement of large amounts of plant material, limited success in dyeing synthetic materials, need for the use of mordants and poor light stability [11]. Overcoming these disadvantages, the aim of this study is to obtain natural dye from waste green and brown walnut (Juglans regia L.) shells for dye and leather industry.In this study, the leather coloration was performed by the dyes produced from green walnut shell (GWS) and brown walnut shell (BWS).

This paper introduces an analytical method for identifying the dyeobtained from these walnut shells which is based on the extraction of colorant from them through a solvent using Soxhlet apparatus. In this study, dyeability of leather with walnut shell extracts have been investigated. Untreated leathers were dyed with dyes produced from GWS and BWS. Mordant wasused as to its effectiveness to changethe color of the leather. In the study, it was gathered much information on the chemical composition of the dyes produced fromGWSand BWSby using series of analysis.

\section{Material and Methods}

In general, green and brown walnutsareharvested in September when they seem to be richest in active principles. In the present work, GWS and BWS (Photo 1) from one walnut cultivar (Kaman) grown in Turkey, were studied, regarding their dyeing activities.

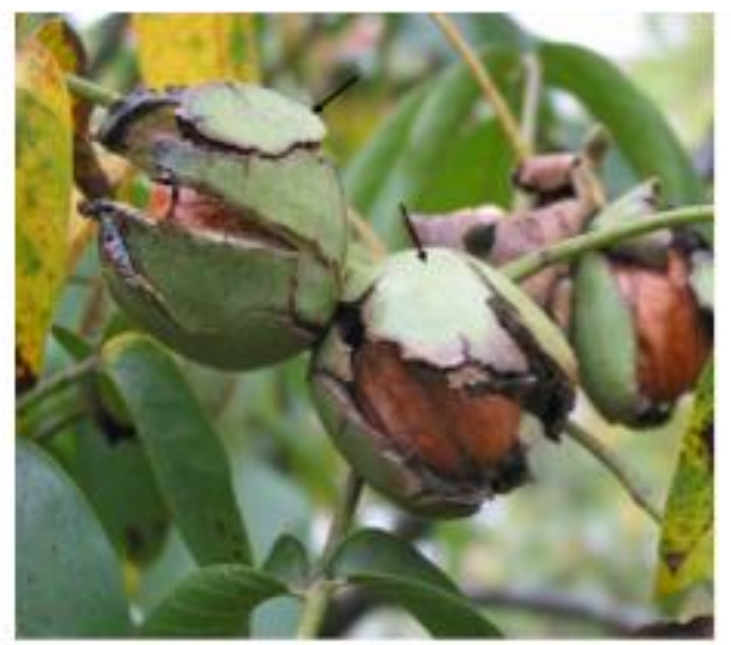

Photo 1. GWS and BWS 
The chemicals used in this study were analytically graded and provided by Merck Co. Following experimental steps were performed toproduce natural dye from GWS and BWS: (a) cracking, shelling, chopping and grinding of these shells (by using grinding mill) to increase the contact surface and decrease the sample size,(b) eliminating humidity from the shells after dried in oven, (c) extraction processing with Soxhlet extraction method by using ethanol solution, (d) evaporating this ethanol solution in controlled way, and (e) mordanting of obtained dyes by using potassium aluminium sulphate (PAS).

At first, we employed the Soxhlet apparatus to extract colorants from GWS and BWS byethanol solvent. The dissolved colorants in ethanol were collected by means of rotary evaporator. In this study, $100 \%$ untreated leather was employed as the main substrate.

Experimental details were as follows

Extraction- $20 \mathrm{~g}$ GWS or BWS, $50 \mathrm{~mL}$ ethanol, $300 \mathrm{~mL}$ DDW, $110^{\circ} \mathrm{C}, 4 \mathrm{hr}$.

Mordanting- $25^{\circ} \mathrm{C}, 4 \mathrm{hr}$.

Dyeing- $20 \mathrm{~g}$ sodium carbonate, $50 \mathrm{~g}$ sodium chloride, $10-20 \mathrm{~mL}$ dye, $60^{\circ} \mathrm{C}, 4 \mathrm{hr}$.

\section{Thin layer chromatography $(T L C)$}

TLC method by aluminum sheet, silicagel $60 \mathrm{f} 254$ was done. For separation of the components from the obtained extract, $0.5 \mathrm{~g}$ was diluted with $1 \mathrm{ml}$ benzene; methanol-chloroform 1:1 was used as mobile phase on $250 \mathrm{~mm}$ silicagel plate; eight spots were put at the starting line. The dye was quickly released from the starting line leading to a single strong brown spot. The compound type can be identified by mean of retardation factor value, $R_{f}$.

$\mathrm{R}_{\mathrm{f}}=\mathrm{h}_{\mathrm{A}} / \mathrm{h}_{\mathrm{S}}$ where $\mathrm{h}_{\mathrm{A}}$ was the average distance from the start to the middle of the spots and $\mathrm{h}_{\mathrm{S}}$ the distance from the start line to the solvent end line.

\section{Colorfastness}

Color characteristics of dyed samples were determined with a Premier Colourscan SS 6200A spectrophotometer using illuminant D65 and $10^{\circ}$ standard observer in terms of CIELab values $\left(\mathrm{L}^{*}, \mathrm{a}^{*}, \mathrm{~b}^{*}\right)$ and color strength (Table 1). Colorfastness to washing/laundering (machine), water, perspiration, light and rubbing tests were conducted according to ISO Standards (15702,11642, 11641, 105-B02 and 11640, respectively) (Table 2) [12-16].

Fastness of the color of leather to machine washing [12] is the resistance to washing under domestic machine laundering in water. In washing leather, not only changes in color can occur in the leather, but colored substances may bleed from it and may stain adjacent textile materials. In "Colorfastness of Leather to Machine Washing Method", the samples of dyed leather in contact with undyed textiles, e.g. multi-fibre strips or wool and cotton, are agitated in a solution of a standard wash detergent $(4 \mathrm{~g} / \mathrm{L}$ ECE Colour Fastness Test Detergent 77) for $30 \mathrm{~min}$ at $40^{\circ} \mathrm{C}$. The samples are rinsed and dried.The change in color of the leather specimen is compared with the original leather sample and the staining of the textiles are assessed with standard Grey Scales.

The colorfastness of leather to water [13] is the resistance to the prolonged action of water. Pre-wetted pieces of wool (W) and cotton (C), or multi-fibre fabric strips, are placed on the test surface of the dyed leather sample, which has been thoroughly wet out in water. The composite specimen is then placed between glass plates under pressure for 3 hours at $37^{\circ} \mathrm{C}$. The specimen and the textile are dried. The change in color of the leather specimen is compared with the original leather sample and of the textile are assessed with standard Grey Scales.

By fastness of color of leather to perspiration [14] is meant its resistance to the prolonged action of an artifical perspiration solution. Samples of leather and textile fabrics, e.g. a multi-fibre strip or pieces of W and C, are thoroughly wetted out separately in an artifical perspiration solution. The textiles are placed on the side of the leather specimen to be tested and the composite specimen is then placed between glass plates under pressure for 3 hours at $37^{\circ} \mathrm{C}$. The specimen and the textile pieces are dried. The change in color of the dyed leather is compared with the original leather sample and the staining of the textiles are assessed with the standard Grey Scales.

Colorfastness of Leather to Light: Xenon Lamp Method [15] is intended to determine the resistance of the color of leather to the action of a standard artificial light source. The Xenon lamp has an emission wavelength profile close to daylight. The side to be tested of the leather sample is exposed to light from a Xenon Lamp, under controlled conditions, along with eight blue dyed wool standards (blue scale). The light fastness is assessed by comparing the fading of the leather with the fading of the blue standards. The fading is typically made in 2 exposure times to better assist the evaluation. The exposure time can be varied depending on the 
lamp intensity and the blue scale level required. To measure up to a maximum blue scale level 3 an exposure of $20 \mathrm{~h}$ and $80 \mathrm{~h}$ (as below) is often sufficient for a quick checking of the light fastness rating.

Colorfastness of Leather to Rubbing Method [16] is intended to determine the transfer of color and the behaviour of the surface of a leather on rubbing with an undyed wool felt.The side of leather to be tested is rubbed with pieces of standard wool felt under a given pressure with a given number of forward and backward motions. The wool felts can be either dry, wetted out in water or wetted with a solution of artifical perspiration at $\mathrm{pH}$ 8.The change in color of the felt and of the leather are assessed with a standard Grey Scales.

Ultraviolet and visible spectroscopy (UV-Vis)

UV-Vis spectroscopic analyses were performed on a Shimadzu UV-160A spectrophotometer.

\section{Results and Discussion}

\section{$T L C$}

In TLC, the compound type can be identified by means of retardation factor value, indicating $\mathrm{R}_{\mathrm{f}}\left(\mathrm{h}_{\mathrm{A}} / \mathrm{h}_{\mathrm{s}}\right)$. In this study, calculated $\mathrm{R}_{\mathrm{f}}$ values of dyes produced from GWS and BWS were found to be 0.5625 and 0.6775.

\section{Colorfastness}

There were 2 dyes x 1 mordant type x 3 replications for colorfastness to light testing. Mordanting has an important effect not only on colorimetric properties but also on leather shades. Brown color and color shades were obtained in the presence of mordant (PAS) (Table 1).

Table 1. Dyes Exposed to Colorfastness to Light Test

\begin{tabular}{|l|c|c|c|c|c|c|c|c|c|c|}
\hline Material & $\begin{array}{c}\text { Color Palette/ } \\
\text { Color Swatch }\end{array}$ & L & a & b & Red & Green & Blue & H & S & B \\
\hline GWS dye & & 12 & 0 & 0 & 32 & 32 & 32 & 0 & 0 & 13 \\
& & & & & & & & & & \\
\end{tabular}

H: Hue, S: Saturation, B: Brightness

Mordanted dyesproduced from GWS and BWS were tested for colorfastness to light in accordance with related test method to obtain CIELab ratings, determining the specific color coordinates $\mathrm{L}^{*} \mathrm{a} * \mathrm{~b}^{*}$. When looking at the effect of exposure, all dyes had significant effect for L* (lightness) when exposed to 24 hours of light. L* showed that leather dyed with GWS was darker than leather dyed with BWS after lightfastness testing. Leathers dyed with GWS and BWS had significant difference when looking at the L* coordinate. $\mathrm{a}^{*}$ coordinates were not similar after light exposure for dyed leathers. Leathers dyed with GWS and BWS were dark gray and brown $\left(\mathrm{b}^{*}\right)$, and control sample was beige after lightfastness testing (Table 1).

Results of colorfastness to washing/laundering, water, perspiration, light andrubbing tests were given in Table 2 and 3. The change in color of the dyed leathersis compared with the original leather sample and the staining of the textiles are assessed with the standard Grey Scales that are used for assessing changes in color of leather in colorfastness tests. The scale consists of nine pairs of grey color chips each representing a visual difference 
and contrast. The fastness rating goes step-wise fromNote $5=$ no visual change (best rating)to Note $1=$ a large visual change (worst rating).

Colorfastness (washing/laundering, water, perspiration, light and rubbing fastness) test results for leather sample dyed with GWSand control leather sample were the same (gray scale rating of 3 to 5), meaning that there was no change between them. However,colorfastness test results of leather dyed withBWSwere different (gray scale rating of 2 to 4+) (Table 2,3). Leather dyed with BWS performed better than the control and leather dyed with GWS when tested for light fastness (Table 2).

Table 2. Colorfastness (washing/laundering, water and perspiration fastness) test results for leather samples dyed with GWS and BWS

\begin{tabular}{|c|c|c|c|c|c|c|c|c|c|c|c|c|c|c|c|c|c|c|c|c|c|}
\hline \multirow[b]{2}{*}{ 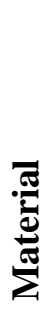 } & \multicolumn{7}{|c|}{ Washing/laundering fastness } & \multicolumn{7}{|c|}{ Water fastness } & \multicolumn{7}{|c|}{ Perspiration fastness } \\
\hline & W & $\mathbf{A}$ & $\mathbf{P}$ & $\mathbf{N}$ & $\mathbf{C}$ & $\mathbf{A}$ & 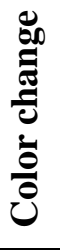 & $\mathbf{W}$ & $\mathbf{A}$ & $\mathbf{P}$ & $\mathbf{N}$ & $\mathbf{C}$ & $\mathbf{A}$ & 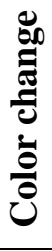 & $\mathbf{W}$ & $\mathbf{A}$ & $\mathbf{P}$ & $\mathbf{N}$ & $\mathbf{C}$ & $\mathbf{A}$ & 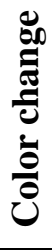 \\
\hline 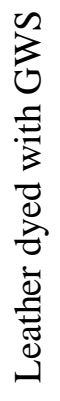 & $\frac{\curvearrowleft}{\gamma}$ & $\frac{\curvearrowleft}{\gamma}$ & $\stackrel{n}{\gamma}$ & $\stackrel{\curvearrowleft}{\gamma}$ & $\frac{\curvearrowleft}{\gamma}$ & $\stackrel{\curvearrowleft}{\gamma}$ & $m$ & $\frac{n}{\gamma}$ & $\stackrel{\curvearrowleft}{\gamma}$ & $\stackrel{\curvearrowleft}{\gamma}$ & $\frac{n}{\gamma}$ & $\frac{\curvearrowleft}{\gamma}$ & $\frac{\curvearrowleft}{\gamma}$ & $\nabla$ & $\frac{\curvearrowleft}{\gamma}$ & $\frac{n}{\gamma}$ & $\stackrel{\curvearrowleft}{\gamma}$ & $\stackrel{\swarrow}{\gamma}$ & $\stackrel{\swarrow}{\gamma}$ & $\frac{\curvearrowleft}{\gamma}$ & ४ \\
\hline 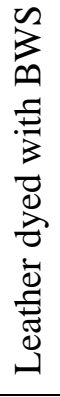 & $\stackrel{+}{+}$ & $\stackrel{+}{+}$ & $\stackrel{+}{+}$ & $\frac{+}{m}$ & $\stackrel{\curvearrowright}{\curvearrowright}$ & $\stackrel{+}{+}$ & $\stackrel{\tilde{N}}{\dot{N}}$ & $\stackrel{+}{+}$ & $\stackrel{+}{+}$ & $\stackrel{+}{+}$ & $\frac{d}{m}$ & $\frac{d}{m}$ & $\stackrel{+}{+}$ & $\nabla$ & $\stackrel{+}{\forall}$ & $\stackrel{+}{+}$ & $\stackrel{+}{+}$ & $\frac{ \pm}{m}$ & $\frac{ \pm}{m}$ & $\stackrel{+}{+}$ & 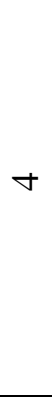 \\
\hline 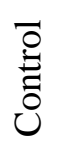 & $\stackrel{\curvearrowleft}{\gamma}$ & $\stackrel{\curvearrowleft}{\gamma}$ & $\stackrel{\curvearrowleft}{\gamma}$ & $\stackrel{\curvearrowleft}{\gamma}$ & $\stackrel{\wp}{\gamma}$ & $\stackrel{n}{\gamma}$ & $m$ & $\frac{n}{\gamma}$ & $\frac{\curvearrowleft}{\gamma}$ & $\stackrel{n}{\gamma}$ & $\frac{\curvearrowleft}{\gamma}$ & $\frac{\wp}{\gamma}$ & $\stackrel{\wp}{\gamma}$ & $\nabla$ & $\stackrel{\Re}{\gamma}$ & $\stackrel{n}{\gamma}$ & $\stackrel{\curvearrowleft}{\gamma}$ & $\stackrel{n}{\gamma}$ & $\stackrel{\curvearrowleft}{\gamma}$ & $\stackrel{\wp}{\gamma}$ & $\nabla$ \\
\hline
\end{tabular}

W: Wool, A: Acrylic, P: Polyester, N: Nylon, A: Acetate

Table 3. Colorfastness (light and rubbing fastness) test results for leathers dyed with GWS and BWS

\begin{tabular}{|l|c|c|c|}
\hline \multirow{2}{*}{ Material } & Light fastness & \multicolumn{2}{|c|}{ Rubbing fastness } \\
\cline { 3 - 4 } & & Dry & Wet \\
\hline Leather dyed with GWS & 2 & $4+$ & $3 / 4$ \\
\hline Leather dyed with BWS & $3-4$ & $3 / 4$ & 2 \\
\hline Control leather & 2 & $4+$ & $3 / 4$ \\
\hline
\end{tabular}

\section{UV-Vis}

The resulting spectra from UV-Vis analysis of the dyes at one concentration $(30 \mu \mathrm{g} / \mathrm{mL})$ are shown in Figure 
1. The peaks appear around $\lambda=667,270$ and $632 \mathrm{~nm}$ for dye produced from GWSand 303 and $910 \mathrm{~nm}$ wavelengths for dye produced from BWS.
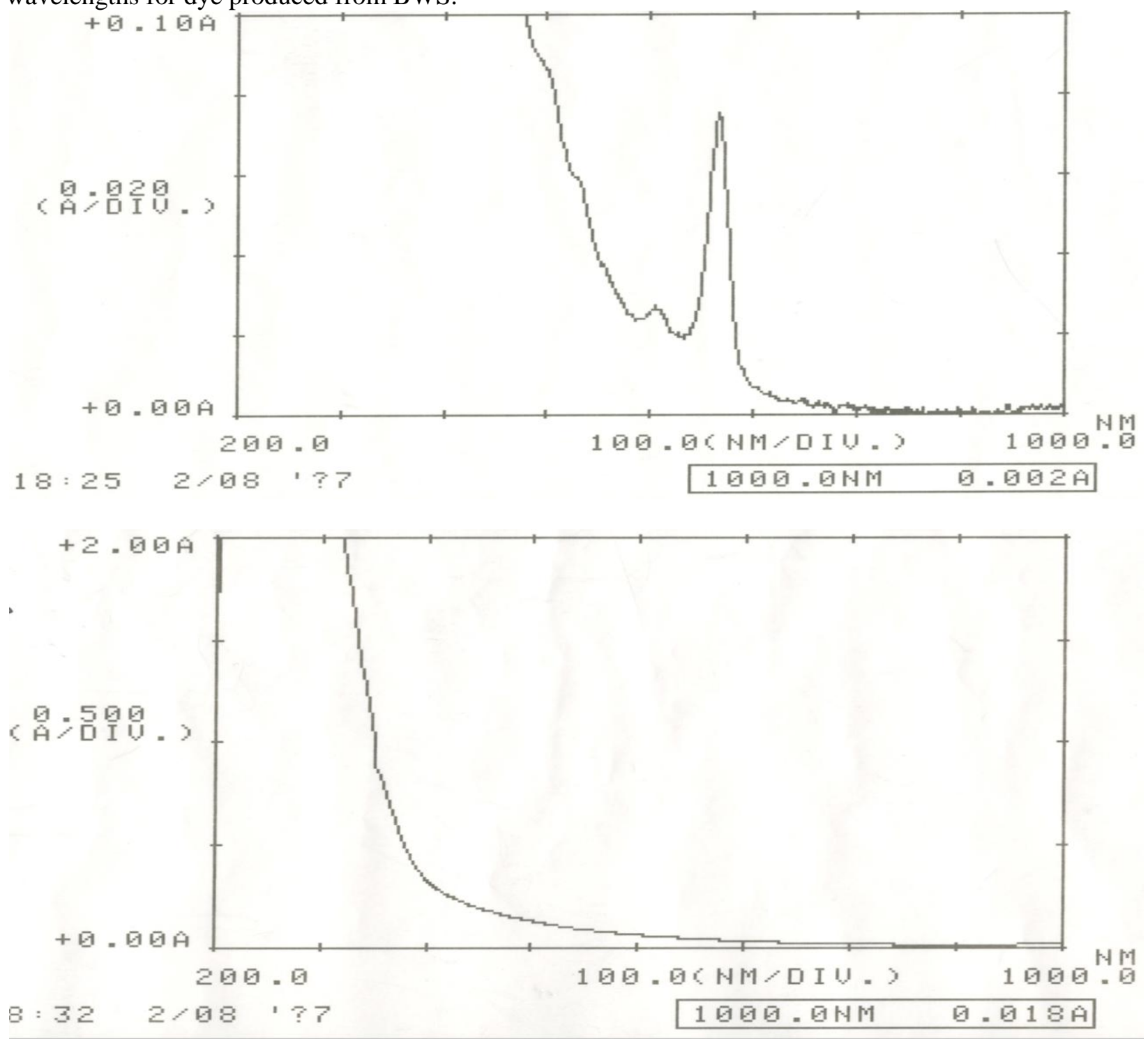

Figure 1. UV-Vis spectra of the dyesproduced from GWS (above) and BWS (below)

\section{Conclusions}

Natural dyes are excellent for their soft and lustrous pastel colors. They give harmonizing colors. Sometimes it is possible to obtain some brilliant colors from natural dyes using mordants. Dyes of natural origin are great for color experimentation as any variation in the concentration of dye, mordant, types of water, soil and climate give variation in colors. Moreover, using shells as a source of dye will increase the value of the walnut production, as well as offering utilization for a by-product, which is produced in large quantities. After many experiments, in this research, by adding $50 \mathrm{~mL}$ ethanol and $300 \mathrm{~mL}$ DDW at $110{ }^{\circ} \mathrm{C}$ Soxhlet extraction in 4 hr, $20 \mathrm{~mL}(\mathrm{pH}=5.4)$ natural dye was obtained from $20 \mathrm{~g}$ BWS as optimum value. In this study, leather coloration was performed bythe dyes produced fromGWS and BWS.The results indicated that leathers dyed with BWS performed better fastness properties when tested for light fastness, have higher color values and better dye penetration compared to those dyed with GWS.Overall, GWS and BWS dyes were not effective in dyeing leather considering rubbing, washing/laundering, water and perspiration fastness tests. However, they were different colorants. In conclusion, dyes produced from GWS and BWS are interesting and attractive due to tonal effects created by them. Luminous effect was observed in the dyed leathers. It is uncommon, preferred and economically valuable for leather industry. The main idea of this study is to introduce the chemical aspects, application methods and luminous properties of dyes produced from GWS and BWS for use 
as a sustainable alternative in leather industry.This study would be a positive step to meet the need of leather industry in Turkey and a good example for cleaner production.

\section{Acknowledgements}

This research has been supported by Ömer Halisdemir University Scientific Research Projects Coordination Unit. Project Number: FEB 2016/04-BAGEP, 2016. Some part of this study was presented in $3^{\text {rd }}$ International Conference on Engineering and Natural Science (Budapest, Hungary) and its abstract was published in Book of Abstract of this conference.The authors would like to thank Chemistry Department of Ömer Halisdemir University for laboratory conditions and instrumental analyses, Erzin Leather Industry and Trade Company (Nigde, Turkey) and Asim Erzin for applying the produced dye on the untreated leather samples, Eksoy Chemical Industry and Trade Inc. (Adana, Turkey), Celal Özgüven and Ayten Baş for performing colorfastness (light, rubbing, washing/laundering, water and perspiration fastness) tests.

\section{References}

[1] J-S. Hwang and S-Y. Park, "Application of green walnut husk of juglans regia linn and effect of mordants for staining of silk," Journal of Convergence Information Technology, vol. 8, pp. 279-283, 2013.

[2] M. Carvalho, P. J. Ferreira, M. S. Mendes, R. Silva, J. A. Pereira, C. Jerónimo and B.M. Silva, "Human cancer cell antiproliferative and antioxidant activities of Juglans regia L.," Food and Chemical Toxicology, vol. 48, pp. 441-447, 2010

[3] V. K. Gupta and Suhas, "Application of low-cost adsorbents for dye removal-A review," Journal of Environmental Management, vol. 90, pp. 2313-2342, 2009.

[4] E. Forgacs, T. Cserháti and G. Oros, "Removal of synthetic dyes from wastewaters: a review," Environment International, vol. 30, pp. 953-971, 2004.

[5] H. S. Rai, M. S. Bhattacharyya, J. Singh, T. K. Bansal, P. Vats and U. C. Banerjee, "Removal of dyes from the effluent of textile and dyestuff manufacturing industry: a review of emerging techniques with reference to biological treatment", Critical Reviews in Environmental Science and Technology, vol. 35, pp. 219-238, 2005.

[6] Y. Yang, G. Wang, B. Wang, Z. Li, X. Jia, Q. Zhou and Y. Zhao, "Biosorption of acid black 172 and congo red from aqueous solution by nonviable Penicillium YW 01: Kinetic study, equilibrium isotherm and artificial neural network modelling," Bioresource Technology, vol. 102, pp. 828-834, 2011.

[7] H. B. Senturk, D. Ozdes and C. Duran, "Biosorption of Rhodamine 6G from aqueous solutions onto almond shell (Prunus dulcis) as a low cost biosorbent," Desalination, vol. 252, pp. 81-87, 2010.

[8] V. Vimonses, B. Jin and C. W. K, "Chow insight into removal kinetic and mechanisms of anionic dye by calcined clay materials and lime", Journal of Hazardous Materials, vol. 177, pp. 420-427, 2010.

[9] Y. N. Wang, H. X. Wang, Z. J. Shen, L. L. Zhao, S. R. Clarke, J. H. Sun, Y. Y. Du and G. L. Shi, "Methyl palmitate, an acaricidal compound occurring in green walnut husks," Journal of Economic Entomology, vol. 102, pp. 196-202, 2009.

[10] M.Mirjalili, K. Nazarpoor and L. Karimi, "Extraction and identification of dye from walnut green husks for silk dyeing," Asian Journal of Chemistry, vol. 23, pp. 1055-1059, 2011.

[11] G.W. Taylor, "Natural dyes in textile applications," Review of Progress in Coloration, vol. 16, pp. 5362, 1986.

[12] ISO International Organization for Standardization, 2017, "ISO 15702. Leather-Tests for colour fastness-Colour fastness to machine washing", June 8, 2017. https://www.iso.org/standard/28714.html

[13] ISO International Organization for Standardization, 2017, "ISO 11642. Leather-Tests for colour fastness-Colour fastness to water", June 8, 2017. https://www.iso.org/standard/54446.html

[14] ISO International Organization for Standardization, 2017, "ISO 11641. Leather-Tests for colour fastness-Colour fastness to perspiration", June 8, 2017. https://www.iso.org/standard/54445.html

[15] ISO International Organization for Standardization, 2017, "ISO 105-B02. Textiles-Tests for colour fastness-Part B02: Colour fastness to artificial light: Xenon arc fading lamp test", June 5, 2017. https://www.iso.org/standard/65209.html

[16] ISO International Organization for Standardization, 2017, "ISO 11640. Leather-Tests for colour fastness- Colour fastness to cycles of to-and-fro rubbing", June 5, 2017.

https://www.iso.org/standard/54444.html 